\title{
26 Research Square \\ Climatic data provide clues on the geographic origin of a spider invasion in the Americas
}

Laura Marcela Segura-Hernández ( $\square$ laurasegura.bio@gmail.com )

University of Nebraska-Lincoln https://orcid.org/0000-0002-1165-3889

\section{Gilbert Barrantes}

Universidad de Costa Rica Escuela de Biologia

\section{Eduardo Chacón-Madrigal}

Universidad de Costa Rica Escuela de Biologia

\section{Adrián García-Rodríguez}

Universidad Nacional Autonoma de Mexico

\section{Research Article}

Keywords: Species Distribution Modeling, biogeography, Cyrtophora citricola, MESS, Araneidae, Mediterranean, South Africa

Posted Date: July 30th, 2021

DOI: https://doi.org/10.21203/rs.3.rs-572646/v1

License: (1) (1) This work is licensed under a Creative Commons Attribution 4.0 International License. Read Full License 


\section{Abstract}

Identifying the source population of invasive species is important to assess the distribution and potential effects in the invaded area. The araneid spider Cyrtophora citricola is widely distributed in Europe, Asia, and Africa; however, in the last twenty years, it has been reported in several countries across the Americas. To date, the geographic origin of the populations established in America remains unclear, but considering the successful colonization after its recent arrival, a high environmental similarity between the invaded and native geographic distributions is expected. In this study, we compared the environmental characteristics of two possible native regions (southern Africa and the Mediterranean) and the invaded region (America), to determine the more likely origin for the populations established in America. We found that the South African populations of $C$. citricola occupy environments with similar climatic conditions to those of the American populations, and these similarities are greater than the ones shared with the Mediterranean populations. Therefore, our results support a Southern African, rather than a Mediterranean origin for the populations established in America. In addition, our results also show that populations in America are expanding to environments that differ from those of the native populations. Further studies, assessing intrinsic (e.g. physiological tolerances, plasticity, behavior, reproduction) and extrinsic (physical barriers, predator release) factors could provide further information to disentangle the mechanisms behind this expansion.

\section{Declarations}

\section{Funding}

AGR was financially supported by Dirección General de los Asuntos del Personal Académico (DGAPA) of the National Autonomous University of Mexico; and GB was supported by the Vicerrectoría de Investigación of the Universidad de Costa Rica (project C0-252).

\section{Conflicts of interest}

The authors declare that they have no conflict of interest.

\section{Availability of data and material and Code availability}

The data used is available as Online Supplementary Material (Online Resource 1) and in online databases (GBIF.org; http://splink.cria.org.br/); the code used is available upon request to the corresponding author.

\section{Authors contribution}

All authors developed the concept, LSH and AGR performed the analyses, LSH wrote the main draft of the manuscript and all authors provide revisions for the final version.

\section{Acknowledgments}


We would like to thank Dr. Angela Chuang and Dr. Ren Chu Cheng for providing information about the occurrence of this species in United States and Africa, Dr. Ingi Agnarsson for sharing the preliminary results of the phylogenetic analysis of Cyrtophora, and Dr. Yael Lubin for the guidance and valuable information about this spider's natural history. We also thank Dirección General de los Asuntos del Personal Académico (DGAPA), National Autonomous University of Mexico for supporting AGR as postdoctoral fellow at Instituto de Biología, UNAM ; and the Vicerrectoría de Investigación of the Universidad de Costa Rica (project C0-252) for providing financial support to GB.

\section{Introduction}

The arrival and establishment of any species on a recipient area is a process that depends primarily on the species' dispersal capacity, the propagule pressure (Simberloff 2009), and the environmental similarity between original and recipient areas (Brown et al. 1996; Peterson 2003). In general, the probability of a species establishing in a new area increases with the similarity of the environmental conditions between the original and new areas (Peterson 2003; Wiens and Graham 2005). In the new establishing areas, the interactions with the local biota are unpredictable, but knowing the interactions and ecological requirements of species in their original area could provide useful insights of their possible effects with the native biota in the new regions (Peterson 2003; Wiens and Graham 2005).

Biological invasions are common in nature, but long-distance dispersal events are rare, because they are often restricted by physical and climatic barriers (Diamond 1984; Peterson 2003; Wiens and Graham 2005). However, in recent years, physical barriers have been easily overcome through human transportation - whether intentionally or not - causing a rapid increase in the rate of long-distance invasion events (Brown et al. 1996; Kobelt and Nentwig 2008; Peterson 2003). The successful establishment of an invasive species in a new area depends on several species intrinsic features such as tolerance to long periods of starvation and desiccation, high reproductive rate, and high dispersal capacity (Foelix 2011; Nedvěd et al. 2011). Spiders are characterized by having these features (Foelix 2011) making them well suited for invading new and distant geographical areas.

Examples of trans-oceanic spider invasions in the Neotropics are scarce (Garb et al. 2004; Laborda and Simó 2008), but there are two well known cases: the recently documented invasion of Latrodectus geometricus from South Africa (Garb et al. 2004; Taucare-Ríos et al. 2016) and the invasion of the araneid Cyrtophora citricola (Forsskål 1775) (sensu lato), which is the focus of the present study (Levi 1997). Cyrtophora citricola is reported as native to the Old World (Levi 1997) - ranging from Africa, Europa to part of Asia - with extensive desert regions separating each group of populations between Europe and Africa. This species has recently invaded the American continent, with the first report in 1996 (Levi 1997). It has now been recorded in several countries of the Americas, ranging from Brazil to Florida in the United States (Alayón-García 2003; Edwards 2006; Levi 1997; Martín-Castejón and Sánchez-Ruiz 2010; Sánchez-Ruiz and Teruel 2006; Víquez 2007). However, the specific region from which this species migrated to America currently remains unknown. Given the environmental differences between the 
regions of its native distribution (Cowling et al. 1996; Köppen et al. 2011; Peel et al. 2007), identifying from which geographical native region the New World populations of $C$. citricola more likely originated, provides information for a better understanding of its expansion and impact in the Americas.

Considering the disjunct native distribution of this species, we hypothesize the Southern African region and the Mediterranean region as the two possible origins for the American invasion. Preliminary molecular phylogenetic analyses suggest a closer relationship between the American and the South African populations than to the Mediterranean populations, although this remains unresolved (Agnarsson et al. unpubl.). The Mediterranean origin is considered as another possible scenario given the higher similarity in morphology and behavior between Mediterranean and American populations, than between the South African and American populations (Y. Lubin pers. comm.). Additionally, there is more intense maritime, commercial trade between the Mediterranean region and America (38542 Twenty-foot Equivalent Units (TEU) in 2016; the American Association of Port Authorities -AAPA) compared to the trading with South Africa (2770 TEU, 7\% of the Mediterranean trade). Considering that many populations of $C$. citricola in the Mediterranean and southern African regions occur near coastal areas (Blanke 1972), and that this species has a long-lasting web, there is a high chance that this species was introduced to America via the merchant marine vessels.

In this study, we first assessed the set of environmental variables that best explain the distribution of $C$. citricola spiders in the Mediterranean and southern African regions. Then, to provide support for the geographic origin of the invasion of $C$. citricola in the Americas, we applied different geographic and environmental approaches to test which of these two sets of climatic information (Mediterranean or southern African) predict more precisely the current distribution of this spider in America. Considering that the invasion of $C$. citricola in America is very recent, we expect that established populations occupy habitats with similar environmental conditions to those of the native region (Peterson 2003; Peterson 2011). Therefore, the environmental variables of the region occupied by $C$. citricola in America will have a higher overlap with the set of variables from the native region than with the non-native region.

\section{Methods}

\section{Study species}

Cyrtophora citricola is an orb-weaving spider that builds a dense, sheet web (Eberhard 2020) (ca. 30-40 $\mathrm{cm}$ in diameter, Leborgne et al. 1998), with an irregular tangle above and below it (Wheeler 1926) (Fig. 1a). C. citricola is a gregarious species that occurs in both colonial (Fig. 1b) and solitary webs, built on diverse plant species and human-constructed structures (Chauhan et al. 2009; Johannesen et al. 2012; Lubin 1980; Madrigal-Brenes 2012; Rypstra 1979; Teruel et al. 2014). Colonies can be massive and often cover the entire crown of bushes and medium-size trees (Barba-Díaz et al. 2014; Chauhan et al. 2009; Edwards 2006; Martín-Castejón and Sánchez-Ruiz 2010; Rao and Lubin 2010).

\section{Species occurrences}


We compiled 2795 geo-referenced occurrence points of $C$. citricola from five different sources. We obtained 258 data points from the Global Biodiversity Information Facility (GBIF.org; accessed on March $29^{\text {th }}$ 2018https://doi.org/10.15468/dl.hi6ahq), 18 from SpeciesLink (http://splink.cria.org.br/, accessed on April $\left.4^{\text {th }}, 2018\right)$, and 662 from the Royal Museum of Central Africa database. We also obtained 78 records from different literature sources (Online Resource 1) and collected 13 points in the field in Costa Rica that we geo-referenced using Google Earth. Additionally, our colleague Angela Chuang kindly provided 1574 data points from USA, collected as part of her own research.

We removed duplicated and inaccurate data points (e.g. points that fell in the ocean) from the database prior to conducting the analyses by projecting all points on a global map. Then we filtered the remaining data using the $\mathrm{R}$ package spThin (Aiello-Lammens et al. 2015) to remove all data points having less than a distance of $5 \mathrm{~km}$ from any other point and guarantee one record maximum per cell according to the resolution of our climatic layers (Online resource 2). With this procedure, we generated 32 data points for South Africa and the Southeastern part of Mozambique (hereafter, the South African region), 108 for the Mediterranean Region and 122 for America (Fig. 2).

\section{Environmental information}

To quantify environmental conditions throughout $C$. citricola's distribution range, we used the 19 Wordlclim's bioclimatic variables for all analyses. We used data from the WorldClim database Version 2 (Fick and Hijmans 2017, http://www. worldclim.org), at a 2.5 arcmin resolution (approximately 20 km² $^{2}$ near the Equator). Additionally, we constructed other three environmental grids using information on monthly precipitation, minimum temperature and wind speed from the same climatic database (Fick and Hijmans 2017). We obtained the mean value from the monthly precipitation layers and then calculated the Average Annual Precipitation (hereafter AAP). We extracted the minimum temperature value for each raster cell within the 12-month layers of minimum temperature to get the Minimum Annual Temperature (hereafter MinAT). Finally, we constructed a Maximum Annual Wind Speed (hereafter MWS) layer, by extracting the maximum speed values for each cell layer within the monthly layers of wind speed. We included this last variable as new-born spiderlings of this species are known to disperse by wind (Johannesen et al. 2012).

For the analyses described below, we created a subset of environmental variables. For each Species Distribution Model (SDM) and the respective multivariate environmental similarity surface (MESS) analyses (Online Resource 3), we selected the subset of variables with the lowest collinearity. For this, we used the step-wise approach coded by M. W. Beck and available at https://gist.github.com/fawda123/4717702, which calculates the Variance-Inflation Factors (VIF).

\section{Analyses}

\section{Model calibration}


To obtain the possible native region of the American $C$. citricola, we created three sets of candidate models: one set for each of the two potential native regions (South Africa, Mediterranean) and one for the invaded region (America). We generated the sets of several candidate SDMs with different parameterizations using the ENMeval R package (Muscarella et al. 2014). We generated each model using variations of two different parameters: (1) regularization multipliers that generate penalty values which help to select more simple models (see Elith et al. 2011; Phillips et al. 2017) (these values range from 0.5 to 5 , at intervals of 0.5 ) and (2) different feature classes (transformations of the environmental variables values, see Elith et al. (2011)): Linear (L), Quadratic-Linear(QL), Hinge (H), and their combinations with Product and Threshold (LQHP y LQHPT) (Phillips et al. 2006; Phillips and Dudík 2008).

We calibrated all candidate models by delimiting an area of $1000 \mathrm{~km}$ around the presence points of each region, so that the calibration area would include enough background area containing both environments where the species could be present and environments where the species is likely absent. To avoid the spatial autocorrelation between testing and training points, we used two different data partitioning methods implemented by Muscarella et al. (2014). For the South African Model, we used the Blocks method, which divides the data in four bins with an equal number of occurrences but allows bins to vary in geographic size (Muscarella et al. 2014). This method has been recommended in cases where spatial extrapolation is needed (Muscarella et al. 2014) such as the case of this region which presents few occurrences that also tend to be grouped (Fig. 2). For the Mediterranean and American models, we used the Checkerboard 2 partitioning method, which, as the blocks method, divides the data in four bins, but facilitates the inclusion of isolated occurrences without altering the geographical size of the bin (Muscarella et al. 2014). Therefore, we considered this method appropriate for the scattered occurrences we have for these two regions.

We selected the model with the best evaluation metric from each set of candidate models and this was the model used for the projections on other regions. To determine the accuracy with which each native model predicted the real known occurrences of spiders in the invaded region, we projected each of the two native models on America. Then we created a third model - the one calibrated on the invaded environmental conditions - and projected it onto the two possible native regions, to cross validate the accuracy of our native models.

To evaluate the performance of each set of models created and select the best fitted for each native region, we used four selection criteria with the following priority order: (i) the lowest 'Minimum training presence' omission rate $\left(\mathrm{OR}_{\mathrm{MTP}}\right)$, (ii) the highest Area Under the Curve $\left(A \cup C_{\mathrm{TEST}}\right)$, (iii) the lowest value of $10 \%$ Training omission rate $\left(\mathrm{OR}_{10}\right)$, and (iv) the lowest number of parameters. For details regarding these criteria, see Muscarella et al. (2014). The model that best fitted the criteria mentioned, was selected as the model to run the posterior projections and analyses.

\section{Geographic and environmental similarity}


We extracted the suitability values assigned by each selected native model to the occurrences of $C$. citricola in America. These values were generated by each model for each cell in the region where it was projected, after correlating and fitting the environmental variables to the occurrences included for the region used for calibration (Warren and Seifert 2011). We compared the suitability values of both native models using a T-test.

To analyze the climatic niche overlap among each native region and the invaded region, we used Schoener's D index (Schoener 1968; Broenniman et al. 2012) and Hellinger's I index (Warren et al. 2008; Broenniman et al. 2012). These indices range from 0 (no niche overlap) to 1 (total niche overlap). We used the same criteria proposed by Rodder and Engler (2011) to interpret the index obtained: values between 0-0.2 indicate no or limited overlap, 0.2-0.4 indicates low overlap, 0.4-0.6 for moderate overlap, 0.6-0.8 represents high overlap and 0.8-1 very high overlap.

Additionally, we calculated the environmental niche overlap using a PCA-env following the approach described by Broennimann et al. (2012). This approach includes three metrics that allowed us to compare the environmental conditions of the American region with those present in each native region. The most relevant parameters in this approach are "Stability", which measures the proportion of environmental conditions shared between two regions (Petitpierre et al. 2012) -in our case the invaded versus each of the two native regions; "Expansion" that refers to the proportion of conditions in which the species is present in the new environment but not in the native environment; and "Unfilling" that shows the proportion of the native niche that do not overlap with the niche occupied in the new environment (Petitpierre et al. 2012; Tingley et al. 2014).

We performed some supplementary analyses, including (i) a multivariate environmental similarity surface (MESS) (Elith et al. 2010) to measure the amount of extrapolation the prediction of each distribution model (SDM) is inferring when projected on a different region (Saupe et al. 2012); (ii) density curves for all the 22 environmental characteristics associated with the occurrences of the three regions, and (iii) a Principal Component Analyses to compare the overall overlap of the three niches. For details of these analyses (i-iii), see Online Resource 3. To estimate the D and I indices, as well as the PCA-env and PCA we used all 22 variables.

\section{Results}

The parameters and evaluation metrics of the three models selected showed an overall good performance, with omission rates below 0.09 and 0.13 , and AUC above 0.8 (Table 1 ). The projection of the South African model predicted a larger environmental suitability for $C$. citricola across America compared to the prediction of the Mediterranean model (Fig. 3). The suitability values obtained for the occurrence points in America from the South African model were slightly higher ( $0.86 \pm 0.10$ SD), than those obtained from the Mediterranean model $(0.82 \pm 0.32 \mathrm{SD})$, however, this difference is not statistically significant $(t=-1.53, g l=141.38, p=0.13$, Fig. $4 a)$. It is worth noting that the MESS map analysis showed that the South African model produces higher extrapolation values than the 
Mediterranean model when projected to America (Online Resource 3, Fig. S.2a). The variables that had the highest contribution for each model are shown in Table S1 (Online Resource 4).

Nonetheless, the projections of the American model to each native region (Figs. 4-5) show that the suitability values assigned by the American Model to the South African occurrences were significantly higher than those assigned to the Mediterranean occurrences ( $t=-4.01, g l=31.19, p=0.0003$, Fig. $4 b$ ), with an average suitability value of $0.13( \pm 0.16, S D)$ for the South African occurrences and $0.01( \pm 0.02, S D)$ for the Mediterranean occurrences. The extrapolation values of the American model projected to the two native regions were not particularly different between each other (Online Resource 3 Fig. S.2b).

The climatic niche overlap between the South African and American populations is moderate to low $(D=0.29, l=0.44)$, but is higher than the overlap between the Mediterranean and American populations $(D=0.12, I=0.20)$. Additionally, according to the PCA-env analysis, the environmental characteristics of the geographic distribution occupied by C. citricola in South Africa had a greater overlap (Stability $58 \%$ ) with the characteristics of its distribution in America, than to those of the Mediterranean distribution (Stability 20\%) (Fig. 6). This result also indicates that this spider has occupied new environmental combinations (Expansion) in America in relation to the conditions existing in the native regions - at least $42 \%$ based on the South African model, and $80 \%$ based on the Mediterranean Model. The first axis of the PCA-env comparing the Mediterranean with America (Fig. 6) was mostly explained by Precipitation variables (Precipitation of the driest month $=19.91 \%$, Precipitation of the warmest quarter $=17.80 \%$, and Precipitation of coldest quarter $=17.12 \%$ ) while the second axis was represented by annual climatic variation (Precipitation seasonality $=51.09 \%$, Temperature annual range $=15.59 \%$, and Maximum Wind Speed=15.21\%). In the PCA-env illustrating the relationship between South Africa and America (Fig. 6), the variables with the highest contribution for the first axis were Precipitation of the driest month (20.67\%), Mean diurnal range (19.47\%), and Precipitation of coldest quarter (18.88\%). For the second axis, the variables with the highest contribution were the same as for the Mediterranean (Precipitation seasonality $=32.43 \%$, MWS $=28.91 \%$ and Temperature annual range $=27.42 \%$ )

The supplementary analyses also showed greater similarities in the environmental conditions between the American and the South African regions, than between American and the Mediterranean region. For instance, the overlap in the distribution of each of the 22 variables (Online Resource 3, Fig. S.3-4), as well as the overlap obtained with the PCA (Online Resource 3, Fig. S.5) also showed a larger similarity of America with the South African region, than with the Mediterranean region.

\section{Discussion}

In this study we focused on identifying the possible geographic origin of the invasion of $C$. citricola in America by determining which of two possible native regions share more environmental characteristics with the invaded region. Our results support that the invasive populations of $C$. citricola in America inhabit environments more similar to the South African region than to the Mediterranean region. When we projected the American model onto the native regions, we obtained a higher suitability for the South 
African region. In addition, both D and I indices, the PCA-env, the density curves, and the PCA also showed that the environmental conditions occupied by C. citricola in America are more similar to those in the South African region than to those occupied by this species in the Mediterranean region.

The successful establishment of a given species in a new geographic area is largely determined by the environmental features of the recipient area and species-specific life-history traits, such as dispersal capability, demographic structure (e.g., sex ratio), and adaptability to different environmental conditions and to novel biotic interactions (e.g., a new set of predators and parasites) (Brown et al. 1996; Guisan and Zimmermann 2000). After arrival, the environmental conditions could play a fundamental role on species establishment (Nuñez and Medley 2011; Peterson 2003; van Wilgen and Richardson 2012). Species arriving to places with similar conditions to those of the native area are more likely to succeed in their establishment than species arriving to sites with a different combination of environmental conditions (Peterson 2003). Given that $C$. citricola is a recent invasion and the significantly higher similarity of the environmental conditions between American populations and South African populations support the hypothesis that this species dispersed from the South African Region to America. This is congruent with preliminary genetic results which also suggest a South African origin for the American populations (Agnarsson et al. unpubl.), but we can not confidently discard different origins for the recent invasion of C. citricola in America, until a more extensive phylogenetic study includes populations from a wide range of the American distribution.

Our analyses also showed that $C$. citricola has occupied in America, during the last two decades, a new set of environmental conditions not present in the native regions analyzed (Fig. 6). This is also evident in the lack of reciprocity between invaded and native regions that resulted in the low suitability values obtained for the native occurrences when the invaded model was projected on both native regions (Figs. 4b-5). Two possible processes could explain these results. First, $C$. citricola in America may not be facing the same environmental and biological constraints as in its native regions (Blanke 1972; Brown et al. 1996). In America, C. citricola could be exploiting resources and tolerating conditions different from those present in the native regions, likely because those conditions are still within the species physiological tolerance thresholds. However, such conditions may not be within the geographic reach of the species in the native regions due to external constraints (e.g. mountain ranges, extensive desert areas, parasites, predators, etc.) (Broennimann et al. 2007). Second, the populations of $C$. citricola in America may have rapidly changed their physiological tolerance thresholds compared to those of native populations, and therefore, adapted to this new set of environmental conditions due to a change of the intrinsic (rather than extrinsic) constraints (Yoshida et al. 2007). However, these two possibilities remain to be examined in further detail, as there are no studies on these issues for this species.

As other invasive species, $C$. citricola has several traits that facilitate its expansion. This spider is a generalist predator, so diet does not represent a major limitation (Chauhan et al. 2009). It has a high reproductive rate: one female can produce several egg sacs during a single reproductive season (Chauhan et al. 2009; Leborgne et al. 1998). It has a dispersal method (ballooning) that allows a rapid expansion into new areas (Teruel et al. 2014), and the species is also highly tolerant of disturbed 
environments - favoring its establishment in open areas around cities (Nedvěd et al. 2011; Sánchez-Ruiz and Teruel 2006; Teruel et al. 2014). However, dense, tropical forested areas apparently limit the expansion of this spider species. Several non-systematic samplings in forested areas conducted close to sites where the species has been observed and over a three-year period showed that the species is absent in rain-dense forests, and very rare at the edge of tropical dry forests (Sandoval and Barrantes unpubl.).

The present study is also, to our knowledge, the first to use different methods comparing environmental conditions to assess the origin of an invasive species. Even though this idea has been previously proposed (Steiner et al. 2008), this is the first study that deduces the more likely invasion source by comparing environmental similarities between the possible native and the invaded regions. However, this approach has some constraints. A general limitation in our results is that the predictions are based on relatively static climatic conditions (exemplified by the environmental trait means collected in a determined period), which might not be representative of the niche for dynamic populations (Elith et al. 2010; Elith and Leathwick 2009) - and this could affect the precision of the predictions obtained (Elith et al. 2010; Guisan and Zimmermann 2000). SDM's limitations have also been addressed before (Araujo and Guisan 2006; Elith et al. 2010), and, in particular, the projections of our SDMs based on the native regions need to be interpreted with caution. Thus, despite that the South African model assigns higher suitability values - though non-significant - to the occurrences in America, its evaluation metrics are lower than those of other models, and its predictions tend to overestimate its suitability (as indicated by the MESS analysis). This is also the region with fewer occurrences recorded, so the distribution of $C$. citricola in South Africa might be undersampled in comparison with the other regions. Hence, our results are not entirely consistent in indicating the most likely native region for the American populations. However, we consider that using different analyses provides additional information that could more certainly indicate which was the native region, if most of these analyses converge on similar conclusions. In this study, most analyses indicate that South Africa is the region of origin of this recent $C$. citricola invasion, since South Africa shows a greater environmental similarity with the invaded region.

The analyses conducted here support the hypothesis that $C$. citricola populations in America are more closely related to those in South Africa than those in the Mediterranean. Our results also provide evidence of the expansion of $C$. citricola into a new set of environmental conditions in America, as a result of either plasticity allowing its rapid adaptation (Yoshida et al. 2007) or the absence of biological or physical constraints present in its native range (Broennimann et al. 2007; Roy et al. 2011). Further studies focusing on physiological performance, adaptation strategies, and biological constraints for the species in both native and invasive populations may help to better understand the processes driving its rapid expansion in the tropical areas of the invaded region.

\section{References}

1. Aiello-Lammens ME, Boria RA, Radosavljevic A, Vilela B, Anderson RP (2015) spThin: An R package for spatial thinning of species occurrence records for use in ecological niche models. Ecography 38:541-545. https://doi.org/10.1111/ecog.01132 
2. Alayón-García G (2003) Cyrtophora citricola (Araneidae), registro nuevo de araña para Cuba. Cocuyo $13: 14$

3. Araujo MB, Guisan A (2006) Five (or so) challenges for species distribution modelling. Biogeography 33:1677-1688. https://doi.org/10.1111/j.1365-2699.2006.01584.x

4. Barba-Díaz RA, Alegre-Barroso A, de la Torre P (2014) Presencia de Cyrtophora citricola (Araneae, Araneidae) en Sancti Spíritus, Cuba. Revista Cubana de Ciencias Biológicas 3:95-98

5. Blanke R (1972) Field Studies on the ecology and ethology of Cyrtophora citricola Forskal (Araneidae) in Andalusia. Forma et function 5:125-206

6. Broennimann O, Fitzpatrick MC, Pearman PB, Petitpierre B, Pellissier L, Yoccoz NG, Thuiller W, Fortin MJ, Randin C, Zimmermann NE, Graham CH, Guisan A (2012) Measuring ecological niche overlap from occurrence and spatial environmental data. Global Ecol Biogeogr 21:481-497. https://doi.org/10.1111/j.1466-8238.2011.00698.x

7. Broennimann O, Treier UA, Müller-Schärer H, Thuiller W, Peterson AT, Guisan A (2007) Evidence of climatic niche shift during biological invasion. Ecol Lett 10:701-709. https://doi.org/10.1111/j.14610248.2007.01060.x

8. Brown JH, Stevens GC, Kaufman DM (1996) The geographic range: size, shape, and internal structure. Annu Rev Ecol Syst 27:597-623. https://doi.org/10.1146/annurev.ecolsys.27.1.597

9. Chauhan R, Sihag V, Singh NP (2009) Distribution and biocontrol potential of chosen spiders. Journal of Biopesticides 2:151-155

10. Cowling RM, Rundel PW, Lamont BB, Arroyo MK, Arianoutsou M (1996) Plant diversity in mediterranean-climate regions. Trends Ecol Evol 11:362-366. https://doi.org/10.1016/01695347(96)10044-6

11. Diamond JM (1984) Distributions of New Zealand birds on real and virtual islands. New Zeal J Ecol 7:37-55

12. Eberhard WG (2020) Spider webs: behavior, function, and evolution. University of Chicago Press, Chicago

13. Edwards GB (2006) Cyrtophora citricola (Araneae: Araneidae): a colonial tentweb orbweaver established in Florida. Entomology Circular 411:5-8

14. Elith J, Kearney M, Phillips S (2010) The art of modelling range-shifting species. Methods Ecol Evol 1:330-342. https://doi.org/10.1111/j.2041-210X.2010.00036.x

15. Elith J, Leathwick JR (2009) Species Distribution Models: ecological explanation and prediction across space and time. Annu Rev Ecol Evol S 40:677-697. https://doi.org/10.1146/annurev.ecolsys.110308.120159

16. Elith J, Phillips SJ, Hastie T, Dudík M, Chee YE, Yates CJ (2011) A statistical explanation of MaxEnt for ecologists. Divers Distrib 17:43-57. https://doi.org/10.1111/j.1472-4642.2010.00725.x

17. Fick SE, Hijmans RJ (2017) WorldClim 2: new 1-km spatial resolution climate surfaces for global land areas. Int J Climatol 37:4302-4315. https://doi.org/10.1002/joc.5086 
18. Foelix RF (2011) Biology of Spiders (3rd Editon). Oxford University Press, New York

19. Garb JE, González A, Gillespie RG (2004) The black widow spider genus Latrodectus (Araneae: Theridiidae): phylogeny, biogeography, and invasion history. Mol Phylogenet Evol 31:1127-1142. https://doi.org/10.1016/j.ympev.2003.10.012

20. Guisan A, Zimmermann NE (2000) Predictive habitat distribution models in ecology. Ecol Model 135:147-186. https://doi.org/10.1016/S0304-3800(00)00354-9

21. Johannesen J, Wennmann JT, Lubin Y (2012) Dispersal behaviour and colony structure in a colonial spider. Behav Ecol Sociobiol 66:1387-1398. https://doi.org/10.1007/s00265-012-1394-4

22. Kobelt M, Nentwig W (2008) Alien spider introductions to Europe supported by global trade. Divers Distrib 14:273-280. https://doi.org/10.1111/j.1472-4642.2007.00426.x

23. Köppen W, VolkenE, Brönnimann S (2011) The thermal zones of the Earth according to the duration of hot, moderate and cold periods and to the impact of heat on the organic world. Meteorol $Z$ 20:351-360. https://doi.org/10.1127/0941-2948/2011/105

24. Laborda A, Simó M (2008) First South American records of Holocnemus pluchei (Scopoli, 1763) and Spermophora senoculata (Dugés, 1836) (Araneae: Pholcidae). Gayana (Concepc) 72:261-265. https://doi.org/10.4067/S0717-65382008000200013

25. Leborgne R, Cantarella T, Pasquet A (1998) Colonial life versus solitary life in Cyrtophora citricola (Araneae, Araneidae). Insectes Soc 45:125-134. https://doi.org/10.1007/s000400050074

26. Levi HW (1997) The American orb weavers of the genera Mecynogea, Manogea, Kapogea and Cyrtophora (Araneae: Araneidae). Bulletin of The Museum of Comparative Zoology 155:215-255

27. Lubin YD (1980) The predatory behavior of Cyrtophora (Araneae: Araneidae). J Arachnol 8:159-185

28. Madrigal-Brenes R (2012) Substrate selection for web-building in Cyrtophora citricola (Araneae: Araneidae). J Arachnol 40:249-251. https://doi.org/10.1636/Hi11-30.1

29. Martín-Castejón Y, Sánchez-Ruiz A (2010) Registros más occidentales de Cyrtophora citricola (Forskal, 1775) (Araneae: Araneidae) en Cuba. Novitates Caribaea 3:83-84

30. Muscarella R, Galante PJ, Soley-Guardia M, Boria RA, Kass JM, Uriarte M, Anderson RP (2014) ENMeval: An R package for conducting spatially independent evaluations and estimating optimal model complexity for Maxent ecological niche models. Methods Ecol Evol 5:1198-1205. https://doi.org/10.1111/2041-210X.12261

31. Nedvěd O, Pekár S, Bezděčka P, Líznarová E, Řezáč M, Schmitt M, Sentenská L (2011) Ecology of Arachnida alien to Europe. Biocontrol 56:539-550. https://doi.org/10.1007/s10526-011-9385-3

32. Nuñez MA, Medley KA (2011) Pine invasions: Climate predicts invasion success; something else predicts failure. Divers Distrib 17:703-713. https://doi.org/10.1111/j.1472-4642.2011.00772.x

33. Peel MC, Finlayson BL, McMahon TA (2007) Updated world map of the Köppen-Geiger climate classification. Hydrol Earth System Sciences 11:1633-1644. https://doi.org/10.5194/hess-11-16332007 
34. Peterson AT (2003) Predicting the geography of species' invasions via ecological niche modeling. Q Rev Biol 78:419-433. https://doi.org/10.1086/378926

35. Peterson AT (2011) Ecological niche conservatism: a time-structured review of evidence. J Biogeogr 38:817-827. https://doi.org/10.1111/j.1365-2699.2010.02456.x

36. Petitpierre B, Kueffer C, Broennimann O, Randin C, Daehler C, Guisan A (2012) Climatic niche shifts are rare among terrestrial plant invaders. Science 335:1344-1348. https://doi.org/10.1126/science.1215933

37. Phillips SJ, Anderson RP, Dudík M, Schapire RE, Blair ME (2017) Opening the black box: an opensource release of Maxent. Ecography 40:887-893. https://doi.org/10.1111/ecog.03049

38. Phillips SJ, Anderson RP, Schapire RE (2006) Maximum entropy modeling of species geographic distributions. Ecol Model 190:231-252. https://doi.org/10.1016/j.ecolmodel.2005.03.026

39. Phillips SJ, Dudík M (2008) Modeling of species distribution with Maxent: new extensions and a comprehensive evalutation. Ecography 31:161-175. https://doi.org/10.1111/j.09067590.2008.5203.x

40. Rao D, Lubin $Y$ (2010) Conditions favoring group living in web-building spiders in an extreme desert environment. Isr J Ecol Evol 56:21-33. https://doi.org/10.1560/IJEE.56.1.21

41. Rödder D, Engler JO (2011) Quantitative metrics of overlaps in Grinnellian niches: advances and possible drawbacks. Global Ecol Biogeogr 20:915-927. https://doi.org/10.1111/j.14668238.2011.00659.x

42. Roy HE, Lawson Handley LJ, Schönrogge K, Poland RL, Purse BV (2011) Can the enemy release hypothesis explain the success of invasive alien predators and parasitoids? BioControl 56:451-468. https://doi.org/10.1007/s10526-011-9349-7

43. Rypstra AL (1979) Foraging flocks of spiders: A study of aggregate behavior on Cyrtophora citricola Forskal (Araneae: Araneidae) in West Africa. Behav Ecol Sociobiol 5:291-300. https://doi.org/10.1007/BF00293677

44. Sánchez-Ruiz A, Teruel R (2006) Acerca de la presencia de Cyrtophora citricola (Forskål, 1775) (Araneae: Araneidae) en Cuba. Boletin de La Sociedad Entomológica Aragonesa 38:335-336

45. Saupe EE, Barve V, Myers CE, Soberón J, Barve N, Hensz CM, Peterson AT, Owens HL, Lira-Noriega A (2012) Variation in niche and distribution model performance: the need for a priori assessment of key causal factors. Ecol Model 237:11-22. https://doi.org/10.1016/j.ecolmodel.2012.04.001

46. Schoener TW (1968) The Anolis lizards of Bimini: resource partitioning in a complex fauna. Ecology 49:704-726

47. Simberloff D (2009) The role of propagule pressure in biological invasions. Annu Rev Ecol Syst 40:81-102. https://doi.org/10.1146/annurev.ecolsys.110308.120304

48. Steiner FM, Schlick-Steiner BC, VanDerWal J, Reuther KD, Christian E, Stauffer C, Suarez AV, Williams SE, Crozier RH (2008) Combined modelling of distribution and niche in invasion biology: a case study of two invasive Tetramorium ant species. Divers Distrib 14:538-545. https://doi.org/10.1111/j.1472-4642.2008.00472.x 
49. Taucare-Ríos A, Bizama G, Bustamante RO (2016) Using global and regional Species Distribution Models (SDM) to infer the invasive stage of Latrodectus geometricus (Araneae: Theridiidae) in the Americas. Environ Entomol 45:1379-1385. https://doi.org/10.1093/ee/nvw118

50. Teruel R, Martín-Castejón Y, Cala F, García GA, Rodríguez-Cabrera TM (2014) Actualización de la distribución de Cyrtophora citricola (Forskal, 1775) (Araneae: Araneidae) en Cuba y las Antillas. Revista Ibérica de Aracnología 25:27-32

51. Tingley R, Vallinoto M, Sequeira F, Kearney MR (2014) Realized niche shift during a global biological invasion. PNAS 111:10233-10238. https://doi.org/10.1073/pnas.1405766111

52. van Wilgen NJ, Richardson DM (2012) The roles of climate, phylogenetic relatedness, introduction effort, and reproductive traits in the establishment of non-native reptiles and amphibians. Conserv Biol 26:267-277. https://doi.org/10.1111/j.1523-1739.2011.01804.x

53. Víquez C (2007) First record of Cyrtophora citricola (Forskål) from Costa Rica, with notes on some related species (Araneae: Araneidae). Boletin de La Sociedad Entomológica Aragonesa 1:385-388

54. Warren DL, Glor RE, Turelli M (2008) Environmental niche equivalency versus conservatism: quantitative approaches to niche evolution. Evolution 62:2868-2883. https://doi.org/10.1111/j.1558-5646.2008.00482.x

55. Warren DL, Seifert SN (2011) Ecological niche modeling in Maxent: the importance of model complexity and the performance of model selection criteria. Ecol Appl 21:335-342. https://doi.org/10.1890/10-1171.1

56. Wheeler WM (1926) Social habits of some Canary Island spiders. Psyche 33:29-31

57. Wiens JJ, Graham CH (2005) Niche conservatism: integrating evolution, ecology, and conservation biology. Annu Rev Ecol Evol Syst 36:519-539.

https://doi.org/10.1146/annurev.ecolsys.36.102803.095431

58. Yoshida T, Goka K, Ishihama F, Ishihara M, Kudo S (2007) Biological invasion as a natural experiment of the evolutionary processes: introduction of the special feature. Ecol Res 22:849-854. https://doi.org/10.1007/s11284-007-0435-3

\section{Tables}

Table 1. Parameters and evaluation metrics of the models selected for each region analyzed. The variance for each value is shown in parenthesis. 


\begin{tabular}{l|c|c|c}
\hline ggion & South Africa & Mediterranean & America \\
\hline ita partition method & Blocks & Checkerboard 2 & Checkerboard 2 \\
\hline :ature Class $^{\mathbf{a}}$ & $\mathrm{H}$ & LQHP & LQ \\
\hline :gularization multiplier $^{\mathbf{b}}$ & 5 & 2 & 2.5 \\
\hline $\mathbf{R}_{\mathrm{MTP}}(\mathrm{var})^{\mathbf{b}}$ & $0.09(0.04)$ & $0.01(0.00)$ & $0.00(0.00)$ \\
\hline $\mathrm{JC}_{\mathrm{TEST}}(\mathrm{var})^{\mathbf{c}}$ & $0.82(0.16)$ & $0.96(0.00)$ & $0.91(0.00)$ \\
\hline $\mathbf{R}_{10}$ (var $^{\mathbf{d}}$ & $0.13(0.07)$ & $0.10(0.00)$ & $0.09(0.00)$ \\
\hline rameters & 7 & 24 & 11 \\
\hline
\end{tabular}

'eature classes: $\mathrm{H}=$ hinge, LQH= Linear-Quadratic-Hinge, LQHP=Linear-Quadratic-Hingeoduct.

$\mathrm{R}_{\mathrm{MTP}}$ : Minimum training presence omission rate.

$\mathrm{UC}_{\mathrm{TEST}}$ : Area Under the Curve.

$\mathrm{R}_{10}: 10 \%$ Training omission rate.

\section{Figures}

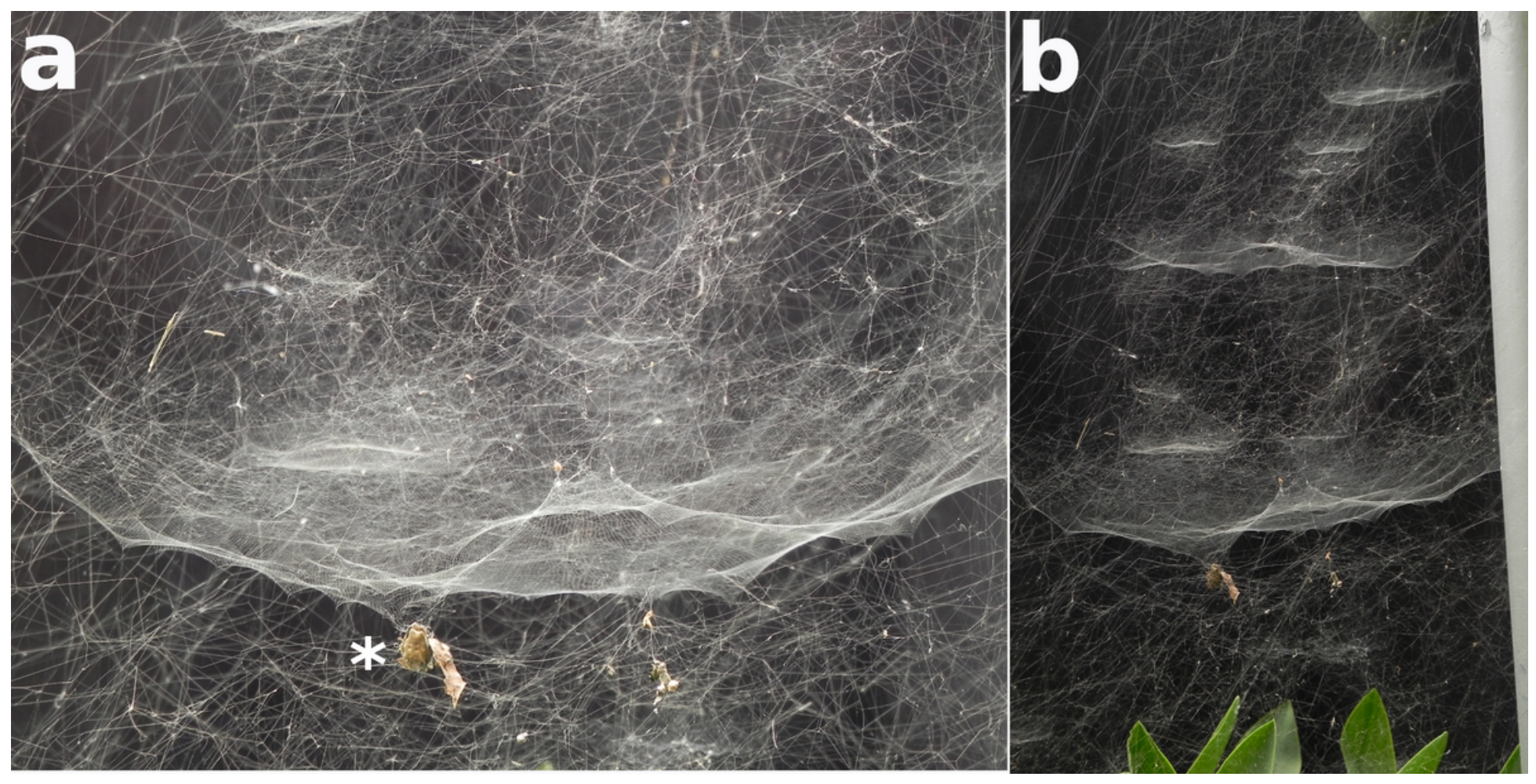

\section{Figure 1}

a. Sheet web of Cyrtophora citricola. The asterisk indicates to the location of the spider, which is at the right of the asterisk. b. Colony of $\mathrm{C}$. citricola built between a plant and a sign post 


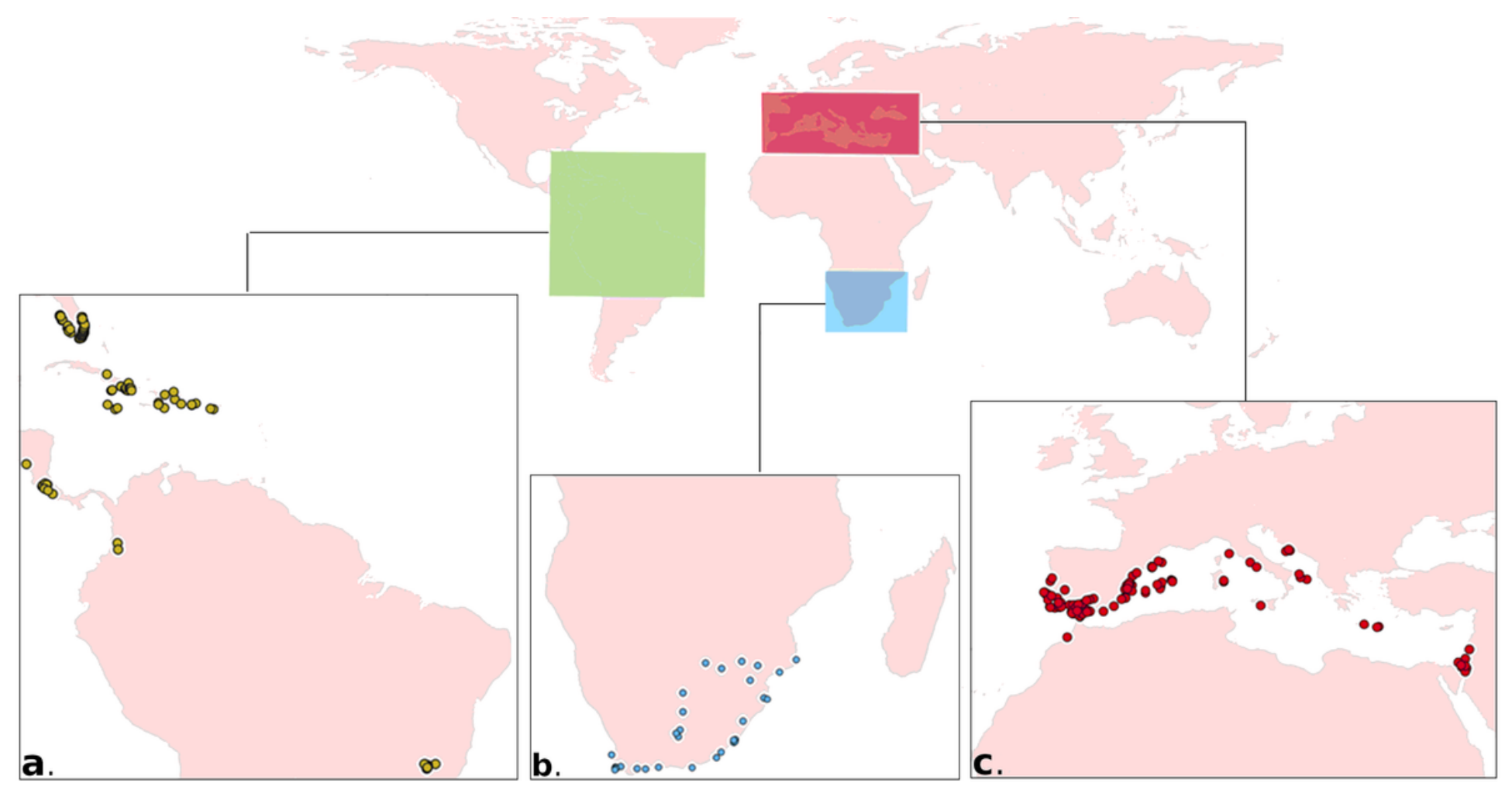

Figure 2

Invaded and native regions of the araneid Cyrtophora citricola, defined as study regions (a-c) to run the SDM: a. represents the occurrences recorded in America, b. the occurrences in the South African region and c. the occurrences for the Mediterranean region
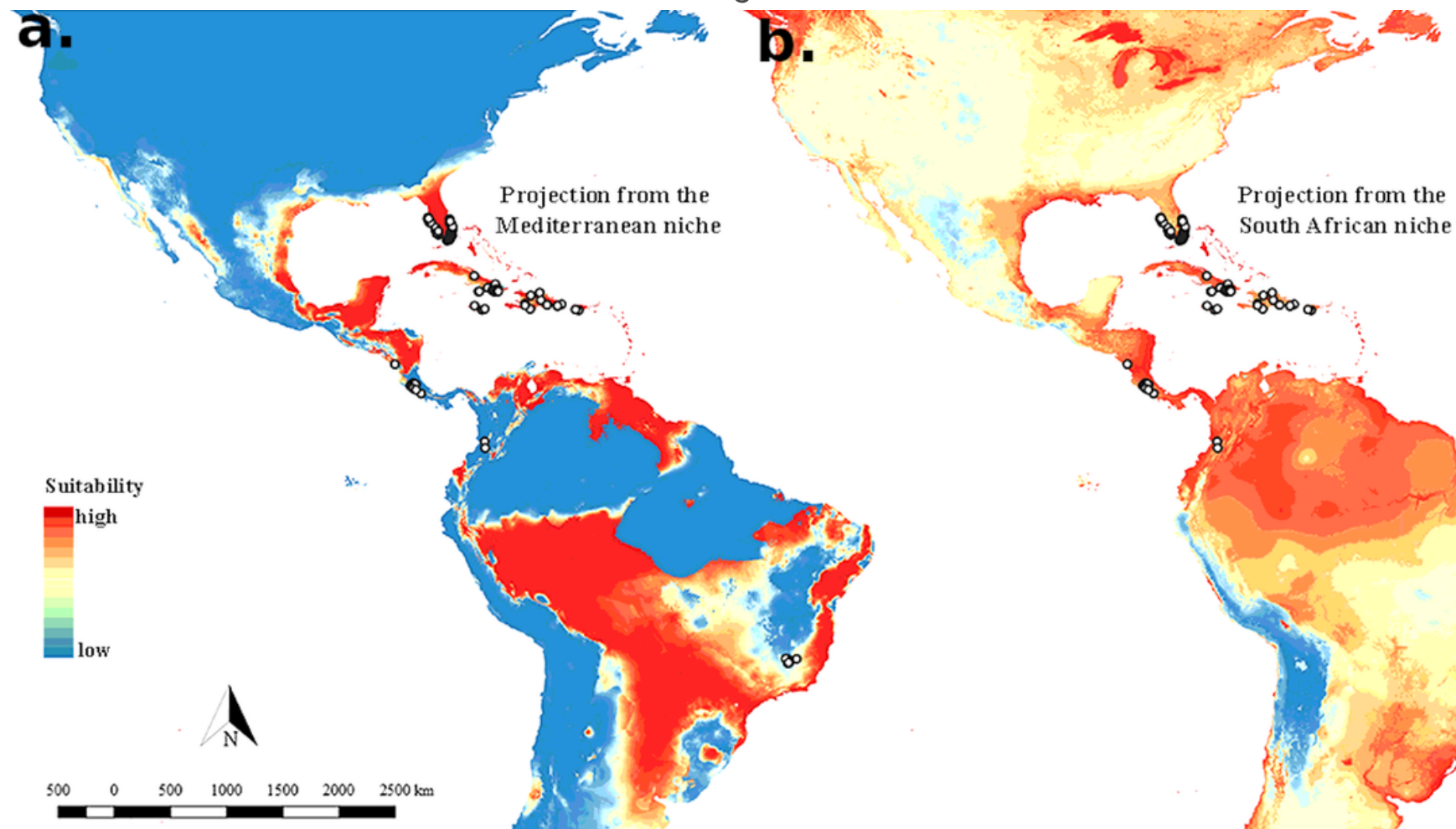

Projection from the

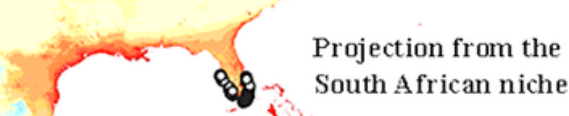
Mediterranean niche




Predictions of the distribution of Cyrtophora citricola in America projected from the two native niche models

\section{a}

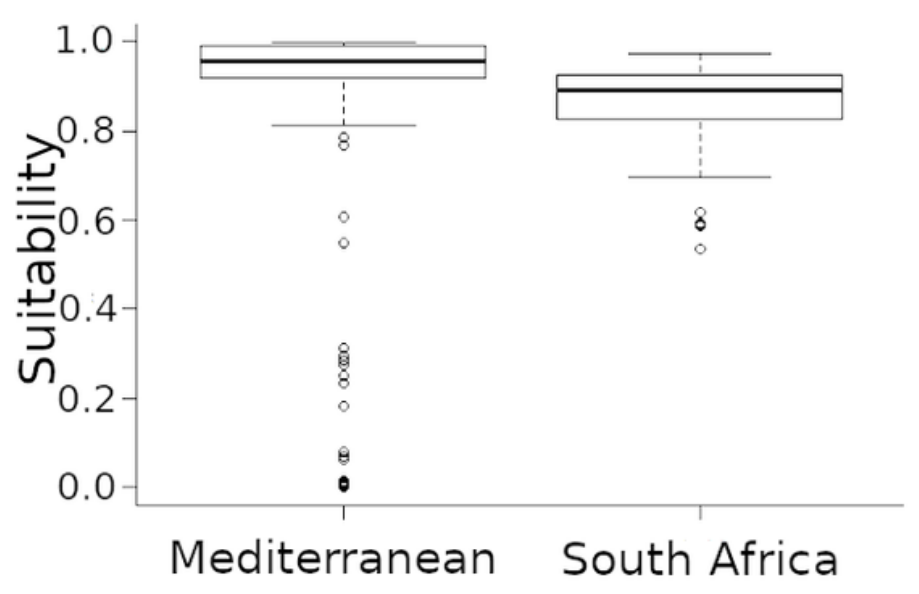



\section{Figure 4}

a. Suitability values obtained by projecting the environmental conditions of the native regions to America. There is no significant difference between the suitability values of the two regions $(t=-1.53, g l=141.38$, $p=0.13)$. b. Suitability values obtained from projecting the American environmental conditions on each native region. Suitability is significantly higher for the South African region $(t=-4.01, g l=31.19, p=0.0003)$. The asterisk indicates the significant difference in suitability values between the regions 


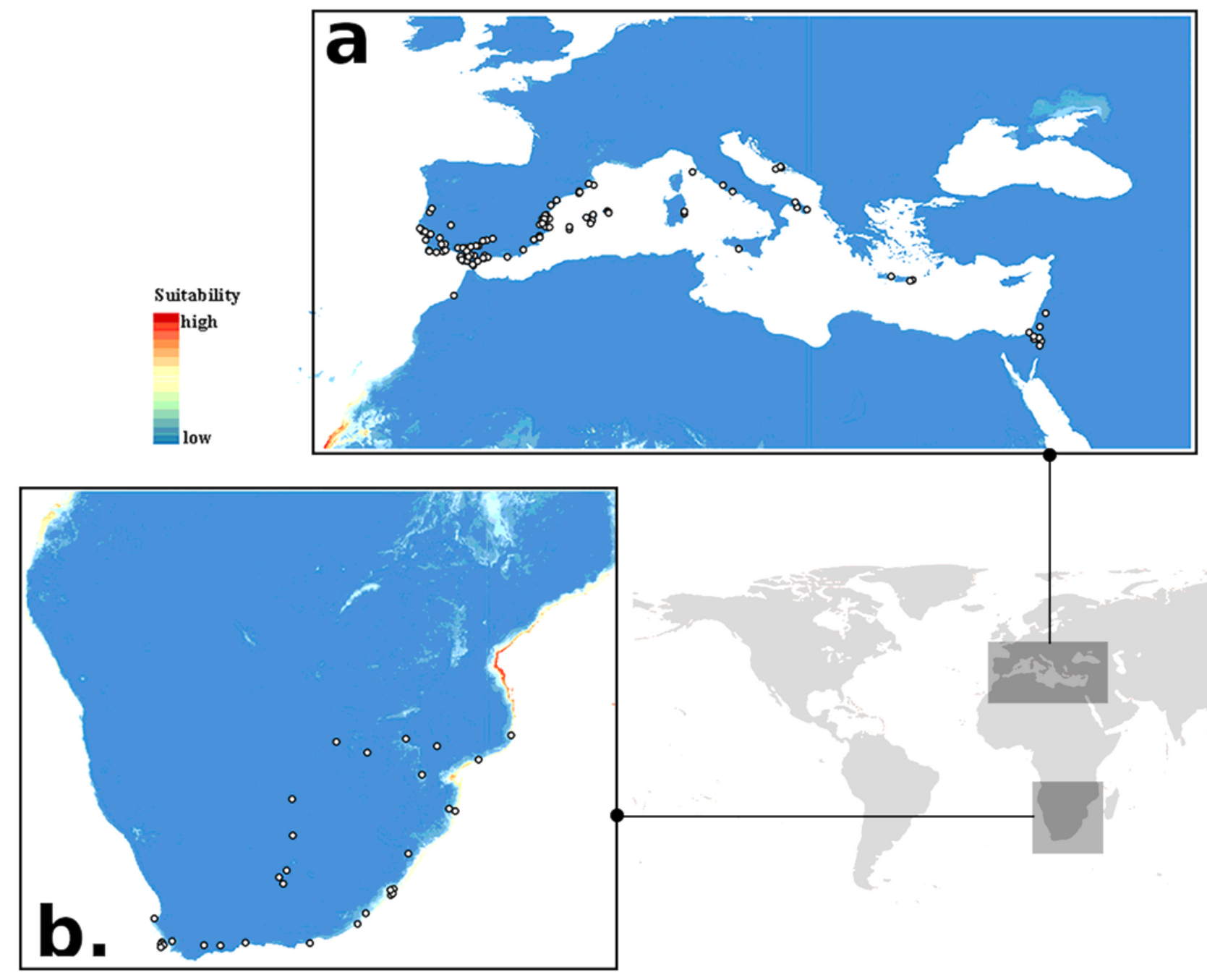

Figure 5

Projection of the model calibrated in America on the two native regions analyzed. a. Projection on the Mediterranean. b. Projection on the South African region
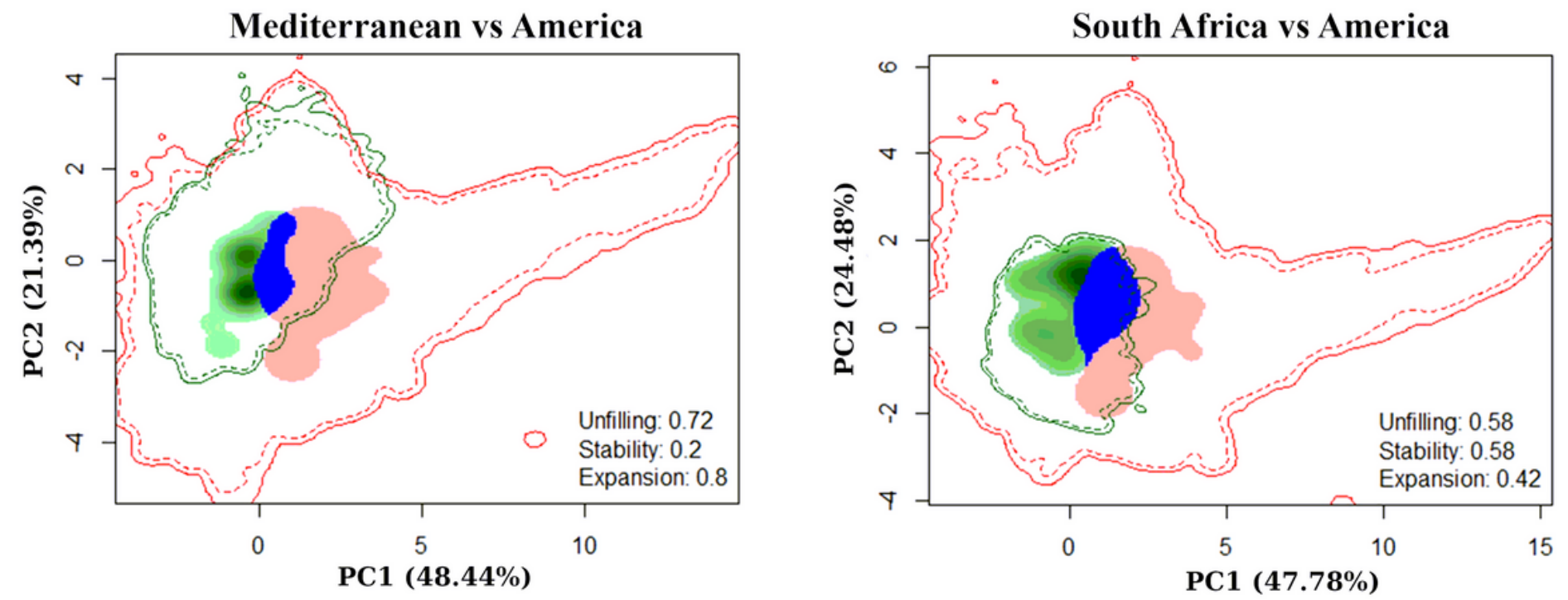


\section{Figure 6}

Climatic niches of $\mathrm{C}$. citricola along the first two axes of an environmental principal component analysis. The left panel shows the comparison of the American and Mediterranean niches, and the right panel compares the American and South African niches. The red, outer line represents the environmental conditions available in America, the green line shows the conditions available in each native site. The pink (towards the right) area represents the environmental conditions where the species has exclusively established in America, the green area (left) the conditions where the species has exclusively established in each native site, and the blue, middle area shows the environmental conditions that overlap between the invaded and the native region

\section{Supplementary Files}

This is a list of supplementary files associated with this preprint. Click to download.

- ESM1.xIsx

- ESM2.docx

- ESM3.docx

- ESM4.docx 